Сельскохозяйственная энтомология, фитопатология

\title{
БИОЭКОЛОГИЧЕСКИЕ ОСОБЕННОСТИ РАЗВИТИЯ ВИШНЕВОЙ МУХИ Rhagoletis cerasi (L. 1758) (Diptera: Tephritidae) В ЦЕНТРАЛЬНО-НЕЧЕРНОЗЕМНОЙ ЗОНЕ РОССИИ
}

\author{
А.С. ЗЕЙНАЛОВ
}

Вишневая муха Rhagoletis cerasi (L. 1758) (Diptera: Tephritidae) в Центрально-Нечерноземной зоне (ЦНЗ) России появилась в конце 1990-х-начале 2000-х годов, что связано с глобальным потеплением и значительным расширением площадей возделывания вишни и черешни в регионе. Благодаря экологической пластичности $\boldsymbol{R}$. cerasi быстро адаптировалась к местным условиям и ежегодно встречается в большом количестве. В настоящей работе впервые определены даты начала вылета, динамика и продолжительность лета мухи в зависимости от погодных условий, периоды откладки яиц, отрождения и питания личинок, ухода их в почву на коконирование, а также особенности диапаузы вредителя в условиях ЦНЗ. Проведена оценка повреждаемости плодов у сортов вишни разного срока созревания. Предложены эффективные методы мониторинга фитофага. Целью работы было изучение фенологических и экологических особенностей развития вишневой мухи на сортах вишни разного срока созревания в ЦентральноНечерноземной зоне России для усовершенствования методов мониторинга, повышения эффективности и экологической безопасности защитных мероприятий. Исследования проводили в 2016-2018 годах в насаждениях вишни Всероссийского селекционно-технологического института садоводства и питомниководства (ВСТИСП, Московская обл., Ленинский р-н, 55,47 с.ш., 37,7 в.д., 124 м над у.м.) на сортах вишни (Prunus cerasus L.) раннего (Сания, Багряная), среднего (Молодежная, Волочаевка) и позднего (Малиновка, Апухтинская) сроков созревания на лабораторном участке и в демонстрационном саду. В зависимости от погодных условий сроки вылета, откладки яиц, отрождения личинок и их ухода на окукливание, а также продолжительность лёта сильно колебались по годам. Начало вылета мух отмечалось при сумме эффективных температур (СЭТ) выше $10{ }^{\circ} \mathrm{C}$ от 191,9 до $268,6^{\circ} \mathrm{C}$ с разницей по датам от 3 до 33 сут; откладки яиц - от 227,4 до $285,1{ }^{\circ} \mathrm{C}$ с разницей до 27 сут; отрождения личинок - от 290,3 до $347,1{ }^{\circ} \mathrm{C}$ с разницей от 2 до 24 сут; ухода личинок на окукливание - от 481,4 до $559,9{ }^{\circ} \mathrm{C}$ с разницей от 5 до 22 сут. Период питания личинок занимал от 18 до 26 сут, продолжительность лёта имаго от 40 до 69 сут. Установлено, что в ЦНЗ у R. cerasi имеет место как однолетняя, так и двухлетняя диапауза. В условиях содержания личинок в специальных садках (под деревьями в саду) после первой зимней диапаузы во взрослых насекомых превратились только 42,0 \% перезимовавших особей. После второй зимней диапаузы таковых было $4,8 \%$ от исходной численности ушедших на диапаузу личинок. На третий год вылетевших мух не зафиксировали. За два года в имаго превратились только 46,8 \% ушедших на диапаузу особей, остальные погибли по разным причинам. Также по годам колебалась поврежденность плодов вишни разного срока созревания: раннего - от 7 до $21 \%$, среднего - от 38 до $57 \%$, позднего - от 61 до $75 \%$. Определение периода вылета и начала развития отдельных стадий фитофага по календарным срокам и фенофазам развития растения-хозяина в разные годы давало противоречивые результаты. Надежный метод сигнализации и мониторинга динамики лёта $R$. cerasi - применение желтых клеевых ловушек с использованием для ориентира СЭТ и визуального наблюдения, в том числе за качеством и степенью зрелости плодов.

Ключевые слова: насекомое, Diptera, Rhagoletis cerasi L., вредитель, биоэкология, диапауза, сумма эффективных температур.

Вишневая муха Rhagoletis cerasi L. (1758) (Diptera: Tephritidae) наиболее экономически значимый фитофаг вишни и черешни в странах Европы (1-3) и Азии (4), в том числе в России (5-7). В последние годы отмечена ее инвазия в Северную Америку $(7,8)$, где этот фитофаг наносит значительный вред наряду с другими видами рода Rhagoletis (R. cingulata, $R$. indifferens и $R$. fausta) (9-11). В исследованиях, проведенных в разных странах и географических зонах, показано существование нескольких рас $R$. cerasi (12-14), однако чаще упоминаются две - южная и северная (1517). Самки северной расы при скрещивании с самцами южной бесплодны, 
самки южной расы при скрещивании с самцами северной дают потомство (16-18). В ряде научных работ подчеркивается, что это явление обусловлено наличием внутриклеточной бактериальной инфекции Wolbachia (1921), наследуемой по материнской линии и распространяющейся в популяциях хозяина по механизму цитоплазматической несовместимости (cytoplasmic incompatibility, CI), которая приводит к эмбриональной смертности при спаривании зараженных самцов с неинфицированными самками или самками с другим штаммом Wolbachia (20-22).

Вместе с тем особое значение имеет вопрос о возможных различиях в биоэкологии южной и северной популяций $R$. cerasi. В последние десятилетия благодаря глобальному потеплению, продвижению культуры вишни и черешни в северные регионы, появлению новых морозоустойчивых сортов и увеличению площадей возделывания существенно расширился ареал фитофага в северной зоне садоводства. Вишневая муха олигофаг. Кроме Prunus sp. (P. cerasus, P. avium, P. serotina, P. mahaleb), она повреждает Lonicera sp. (L. xylosteum, L. tatarica) $(23,24)$. Биоэкология $R$. cerasi тесно взаимосвязана с агроэкологическими условиями, в том числе с климатическими показателями (температура воздуха и почвы в разные периоды, осадки) и фенологией развития растения хозяина (в том числе сортовыми особенностями культуры и качеством плодов), поскольку выживание фитофага зависит от синхронизации появления взрослых особей с наличием плодов посредством диапаузы куколки $(25,26)$.

Еще в конце 1990-х годов и в начале 2000-х годов в ЦентральноНечерноземной зоне (ЦНЗ) встречались единичные особи вишневой мухи. В настоящее время в указанном регионе отмечается ежегодное массовое повреждение вредителем вишни и черешни. На необработанных насаждениях степень поврежденности плодов постоянно нарастает и достигает 70$75 \%$. По данным литературы, при отсутствии защитных мероприятий поврежденность плодов может достигать $100 \%(27,28)$.

В настоящей работе мы впервые описали фенологию и охарактеризовали высокую степень вредоносности $R$. cerasi в Центрально-Нечерноземной зоне. Определены даты начала вылета, динамика и продолжительность лёта мухи в зависимости от погодных условий, периоды откладки яиц, отрождения и питания личинок, их ухода в почву на коконирование, а также особенности диапаузы вредителя в условиях ЦНЗ. На основании оценки повреждаемости плодов вишни предложены эффективные методы мониторинга фитофага.

Целью работы было изучение биоэкологических особенностей и динамики развития вишневой мухи на сортах вишни разного срока созревания в Центрально-Нечерноземной зоне России для усовершенствования методов мониторинга, повышения эффективности и экологической безопасности защитных мероприятий.

Методика. Исследования проводили в 2016-2018 годах в насаждениях вишни Всероссийского селекционно-технологического института садоводства и питомниководства (ВСТИСП, Московская обл., Ленинский р-н, 55,47 с.ш., 37,7 в.Д., 124 м над у.м.) на сортах вишни (Prunus cerasus L.) раннего (Сания, Багряная), среднего (Молодежная, Волочаевка) и позднего (Малиновка, Апухтинская) сроков созревания на лабораторном участке и в демонстрационном саду.

Для отслеживания начала и динамики лёта $R$. cerasi через 5 сут после окончания цветения вишни ранних сроков созревания на 10 учетных площадках на деревьях (по одному дереву на площадке) с южной и юго- 
восточной стороны на внешней проекции кроны развешивали желтые двусторонние клеевые ловушки размером 20×10 см (на высоте 1,7 м). До обнаружения первых вылетевших мух и после 25 июля (до завершения лёта) ловушки осматривали ежедневно, в остальное время - 2-3 раза в неделю. Через 5 сут после обнаружения мух в ловушках ежедневно отбирали по 300 плодов (по 30 с каждой учетной площадки) и осматривали под бинокулярным микроскопом (МБС-10, ОАО «ЛЗОС», Россия), а также ежедневно препарировали 10 самок для установления наличия готовых к откладке яиц. Через 2 сут после обнаружения яиц ежедневно отбирали и осматривали плоды в поиске отродившихся личинок.

Через 2 нед после обнаружения отродившихся личинок ежедневно на наличие выходных отверстий личинок осматривали под лупой по 1000 созревающих (по 100 на каждой учетной площадке) или созревших плодов, не срывая их с деревьев. При выявлении отверстий плоды срывали, разрезали на две части и осматривали под бинокуляром для установления характерных для $R$. cerasi повреждений.

При определении поврежденности разных сортов вишни $R$. cerasi использовали солевой раствор (3). Перед массовым сбором с деревьев каждого сорта случайным методом собирали по 100 плодов, косточки отделяли от мякоти, плоды разрезали на несколько более мелких частей и помещали в насыщенный солевой раствор (350 г соли/л воды). Через 10 мин подсчитывали всплывших личинок.

Чтобы установить длительность диапаузы $R$. cerasi, в период полной спелости в три приема (с интервалом 2 сут) собирали поврежденные плоды, размещали их на сухом песке слоем толщиной 2 см (29) и оставляли в комнатных условиях в режиме естественного освещения (без попадания прямых солнечных лучей). Через 1 нед песок просеивали, отбирали 500 пупариев, размещали в садках по 50 особей на глубине 5 см. Садки представляли собой ящики размером 20×30 см, выстланные с внутренней стороны полиэтиленовой пленкой, заполненной смесью почвы из сада, торфа и песка в соотношении 1:1:1 (толщина слоя 10 см). Садки закапывали в саду до краев ящика на уровне земли с южной стороны деревьев. С трех сторон и сверху (высота крыши 30 см, форма прямоугольная) их накрывали мелкоячеистой сеткой (размер ячеек около 0,8 мм), а с северной стороны делали плотно закрывающееся окно из полиэтилена. В период вегетации отрастающую в садках сорную растительность срезали секатором через окно и удаляли (растения не вырывали, чтобы не нарушить размещение куколок). Незадолго до периода вылета $R$. cerasi внутри садка через окно устанавливали желтые клеевые ловушки. Ловушки с прилипшими к ним мухами удаляли каждую неделю после подсчета последних.

Вычисляли средние значения выборки $(M)$ по датам наблюдений и стандартное отклонение средней $( \pm \sigma)$ по каждому участку наблюдений, значимость различий оценивали по $F$-критерию Фишера. Статистическую обработку табличных данных проводили по Б.А. Доспехову (30) с использованием пакета программы Microsoft Excel.

Результаты. Климатические показатели в годы исследований (по данным метеостанции аэропорта Домодедово) представлены в таблице 1.

Несмотря на значительное влияние резко меняющихся погодных условий в ЦН3, особям $R$. cerasi благодаря экологической пластичности и адаптационным возможностям удавалось в той или иной степени синхронизировать свое развитие с образованием и созреванием плодов растенияхозяина. Степень поврежденности сортов разного срока созревания по го- 
дам варьировала (табл. 2), но обеспечивала выживаемость популяции R. cerasi. С одной стороны, это было связано с возможностью длительной диапаузы стадии куколки в почве (до 10-11 мес, при этом около 6 мес при температуре ниже 5-7 ${ }^{\circ} \mathrm{C}$ ), с другой - со способностью более крупных куколок диапаузировать более 1 года $(29,31,32)$, а также с неодинаковым ответом на воздействие длительных пониженных температур у разных экземпляров куколок (у некоторых этот процесс заканчивается в конце декабря, у других - в марте) (14). По данным литературы, в постдиапаузном развитии куколки имеет место обратимость II стадии, то есть возвращение к I стадии, которая остается в почве до следующего сезона, что, возможно, связано с реакцией на сигналы окружающей среды или на метаболические стимулы (33). На долю куколок, диапаузирующих 1 год или более, может повлиять и состав почвы: в тяжелых глинистых почвах процент дополнительно диапаузирующих куколок увеличивается (34).

1. Температура воздуха и количество осадков в периоды наблюдений за развитием вишневой мухи (Rhagoletis cerasi L.) на сортах вишни (Prunus cerasus L.) разного срока созревания (по данным метеостанции аэропорта Домодедово)

\begin{tabular}{|c|c|c|c|c|c|c|c|c|c|}
\hline \multirow{2}{*}{ Параметр } & \multirow{2}{*}{ Год } & \multicolumn{8}{|c|}{ Месяц } \\
\hline & & III & IV & V & VI & VII & VIII & IX & $\mathrm{X}$ \\
\hline \multicolumn{10}{|l|}{ Среднемноголетнее значение } \\
\hline Отклонение от среднемноголет- & 2016 & $+1,9$ & $+2,3$ & $+1,8$ & $+1,2$ & $+1,7$ & $+2,5$ & $-0,2$ & $-1,1$ \\
\hline ней температуры, ${ }^{\circ} \mathrm{C}$ & 2017 & $+3,4$ & $-0,5$ & $-2,3$ & $-2,5$ & $-1,3$ & $+1,8$ & $+1,2$ & $-0,5$ \\
\hline & 2018 & $+0,5$ & $+1,4$ & $+1,4$ & $+0,3$ & $+1,2$ & $+2,3$ & $+0,9$ & $+0,6$ \\
\hline \multicolumn{10}{|l|}{ Среднемноголетнее значение } \\
\hline количества осадков, мм & & 35 & 37 & 50 & 80 & 85 & 82 & 65 & 59 \\
\hline Отклонение от среднемноголет- & 2016 & 114 & 92 & 126 & 76 & 144 & 204 & 91 & 90 \\
\hline него значения количества осад- & 2017 & 126 & 214 & 168 & 175 & 124 & 83 & 43 & 115 \\
\hline ков, \% & 2018 & 83 & 108 & 142 & 87 & 108 & 54 & 89 & 66 \\
\hline
\end{tabular}

В наших опытах из 500 пупариев, ушедших на зимовку в 2015 году, в следующем году вылетело только 210 мух, что составило 42,0\% от исходной численности. В 2017 году вылетело 4,8 \%, в 2018 году, то есть после третьего сезона диапаузы, в садках не обнаружили ни одной мухи R. cerasi. Всего в течение двух сезонов вылетели 234 мухи (46,8 \% от числа уходящих на диапаузу пупариев в садках). Это высокий процент вылета по сравнению с естественными условиями диапаузирования, где процент вылета имаго сильно колеблется по годам в зависимости от условий среды и иногда может не превышать 5-15\% от исходной численности уходящих на зимовку особей $(35,36)$.

2. Поврежденность плодов вишни (Prunus cerasus L.) разного срока созревания вишневой мухой (Rhagoletis cerasi L.) по годам наблюдения (Московская обл., Ленинский р-н)

\begin{tabular}{|c|c|c|c|c|c|}
\hline \multirow{2}{*}{ Сорт } & \multirow{2}{*}{ Срок созревания } & \multicolumn{3}{|c|}{ Поврежденность, \% } & \multirow{2}{*}{$M \pm \sigma$} \\
\hline & & 2016 год & 2017 год & 2018 год & \\
\hline Сания & Ранний & 17 & 8 & 15 & $13,3 \pm 4,7$ \\
\hline Багряная & Ранний & 21 & 7 & 12 & $13,3 \pm 7,1$ \\
\hline Молодежная & Средний & 57 & 38 & 49 & $48,0 \pm 9,5$ \\
\hline Волочаевка & Средний & 53 & 41 & 43 & $45,7 \pm 6,4$ \\
\hline Малиновка & Поздний & 61 & 75 & 63 & $66,3 \pm 7,6$ \\
\hline $\begin{array}{c}\text { Апухтинская } \\
M \pm \sigma\end{array}$ & Поздний & $\begin{array}{c}64 \\
45,5 \pm 20,9\end{array}$ & $\begin{array}{c}73 \\
40,3 \pm 29,8\end{array}$ & $\begin{array}{c}68 \\
41,7 \pm 23,6\end{array}$ & $68,3 \pm 4,5$ \\
\hline При м еча & $F_{\text {сорт }}>F_{01}, F_{\text {год }}$ & & & & \\
\hline
\end{tabular}

В зависимости от погодных условий начало вылета мух сильно колебалось по годам. Как правило, в ловушках мух обнаруживали на несколько суток позже фактического срока вылета. Разница по датам со- 
ставляла от 3 до 33 сут (табл. 3), а по сумме эффективных температур (СЭТ) выше $10{ }^{\circ} \mathrm{C}$ - от 26,6 до 76,7 ${ }^{\circ} \mathrm{C}$. При этом выбор пороговой температуры для расчета СЭТ на уровне $10{ }^{\circ} \mathrm{C}$ был более целесообразен. В отличие от Южной и Западной Европы, где зима мягкая и температура весной повышается равномерно, в ЦНЗ зима более суровая, наблюдаются резкие скачки температуры воздуха в весенний период. Так, в 2016-2018 годах в марте температура колебалась от -20 до $+10{ }^{\circ} \mathrm{C}$, в апреле - от -5 до $+24{ }^{\circ} \mathrm{C}$. Кратковременное повышение среднесуточной температуры выше $7{ }^{\circ} \mathrm{C}$ могло чередоваться с резким понижением (ниже $0{ }^{\circ} \mathrm{C}$ ) на длительное время, что не способствовало устойчивому развитию куколки. Поэтому расчет СЭТ выше 5 или $7{ }^{\circ} \mathrm{C}$, принятый в Южной, Западной и Центральной Европе $(1,28,37,38)$, в нашей зоне менее пригоден и демонстрирует значительно большее колебание по годам (от 58,7 до 132,2 ${ }^{\circ} \mathrm{C}$ ) по сравнению с СЭТ выше $10{ }^{\circ} \mathrm{C}$ (от 26,6 до 76,7 ${ }^{\circ} \mathrm{C}$ ) (рис. 1). Расчет СЭТ выше $10{ }^{\circ} \mathrm{C}$ для $R$. cerasi осуществлялся и в других научных исследованиях, проведенных на территории России $(14,39)$.

3. Сумма эффективных температур (СЭТ) выше $10{ }^{\circ} \mathrm{C}$ для начала развития отдельных стадий вишневой мухи (Rhagoletis cerasi L.) на растениях вишни по годам наблюдения (Московская обл., Ленинский р-н)

\begin{tabular}{l|c|c|c|c|c|c}
\hline \multirow{2}{*}{ Этап развития } & \multicolumn{2}{c|}{2016 год } & \multicolumn{2}{c|}{2017 год } & \multicolumn{2}{c}{2018 год } \\
\cline { 2 - 7 } & дата & $\mathrm{C} Э$ Т, ${ }^{\circ} \mathrm{C}$ & дата & $\mathrm{C} Э$ Т, ${ }^{\circ} \mathrm{C}$ & дата & $\mathrm{C}$ СТ, ${ }^{\circ} \mathrm{C}$ \\
\hline Обнаружение первых мух в ловушках & 03.06 & 191,9 & 06.07 & 268,6 & 06.06 & 218,5 \\
Начало откладки яиц & 14.06 & 227,4 & 11.07 & 285,1 & 14.06 & 280,8 \\
Начало отрождения личинок & 20.06 & 290,3 & 14.07 & 310,2 & 22.06 & 347,1 \\
Начало ухода личинок на окукливание & 12.07 & 530,3 & 01.08 & 481,4 & 17.07 & 559,9 \\
\hline
\end{tabular}

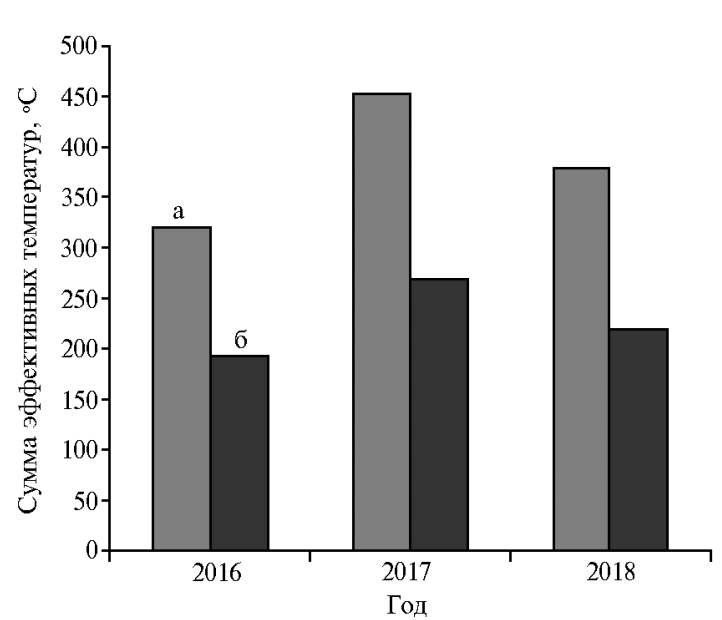

Рис. 1. Суммы эффективных температур к началу вылета вишневой мухи (Rhagoletis cerasi L.) на pacтениях вишни (Prunus cerasus L.) по годам наблюдений при разных порогах: a - выше $7{ }^{\circ} \mathrm{C}$, б - выше $10{ }^{\circ} \mathrm{C}$ (Московская обл., Ленинский р-н).

Период дополнительного питания мух до начала откладки первых яиц (R. cerasi синовигенный вид) занимал от 5 до 11 сут. Разница СЭТ, накопленной к началу откладки яиц, колебалась от 4,3 до $57,7{ }^{\circ} \mathrm{C}$, при этом минимальная разница по СЭТ была зафиксирована между 2017 и 2018 годами и составила 27 сут. Эмбриональный период развития занимал от 3 до 8 сут. Также значительно варьировала по годам разница СЭТ к началу отрождения личинок от 19,9 до $56,8{ }^{\circ} \mathrm{C}$, минимальное значение этого показателя отмечали между 2016 и 2017 годами (24 сут). Период питания первых уходящих на окукливание личинок занимал от 18 до 26 сут с разницей СЭТ для начала ухода личинок в почву от 29,6 до 78,5 ${ }^{\circ}$ С. Минимальную СЭТ зафиксировали в 2017 году с аномально холодной первой половиной вегетационного периода.

Динамика и интенсивность лета $R$. cerasi (рис. 2) во все 3 года исследований различалась несущественно, хотя в 2016-2017 годах численность мух увеличивалась равномерно и, достигнув пика, также равномерно 
снижалась, а в 2018 году наблюдалось три пика численности, что было результатом резкого колебания температуры воздуха. Однако следует подчеркнуть, что максимальная численность мух во все годы наблюдений отмечалась в середине периода лёта, что занимало от 8 до 14 сут. Продолжительность периода лёта $R$. cerasi зависела от погодных условий, состояния кормовой базы (в том числе длительности периода созревания плодов, скорости и чистоты сбора урожая) и составила от 40 (2017 год) до 69 сут (2018 год). В 2016 году лёт продолжался 55 сут.

A

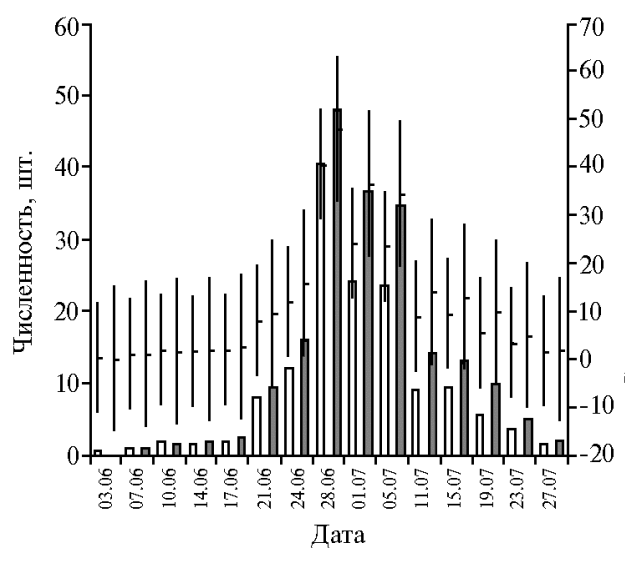

Б

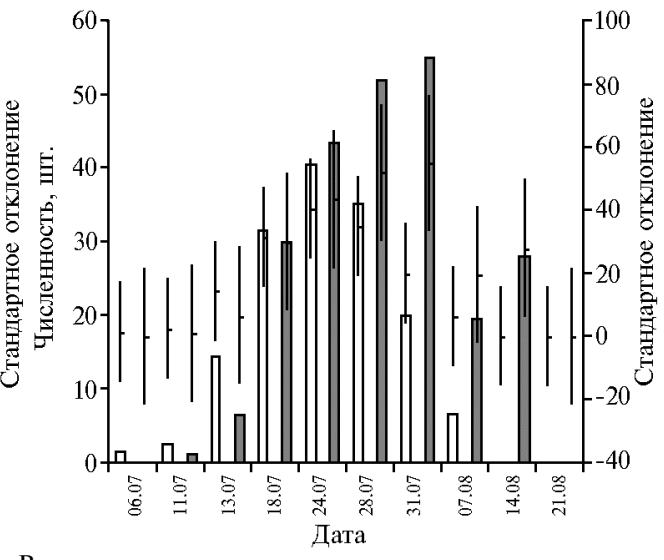

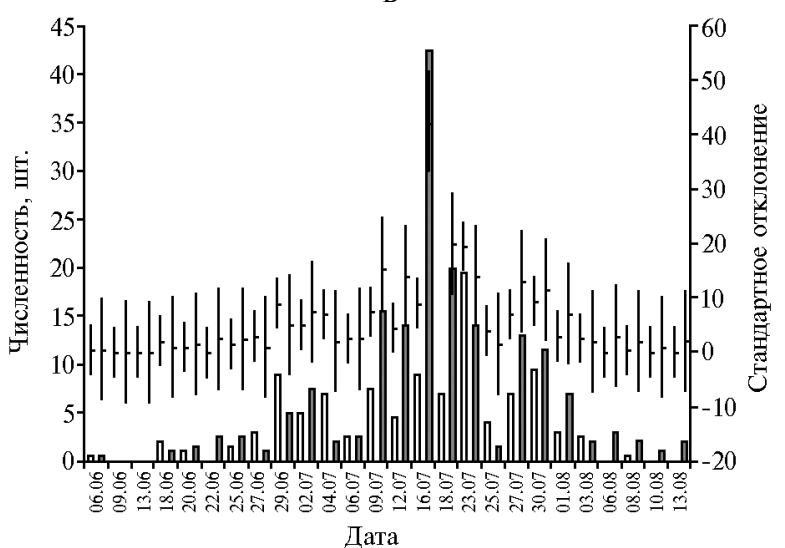

Рис. 2. Динамика лёта (численность в среднем на одну ловушку) вишневой мухи (Rhagoletis cerasi L.) на растениях вишни (Prunus cerasus L.) в 2016 (А), 2017 (Б), 2018 годах (В) на лабо-

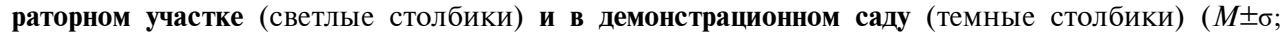
Московская обл., Ленинский р-н).

В ЦНЗ начало выхода $R$. cerasi из зимней диапаузы и развитие последующих стадий сильно колебались как по времени, так и по СЭТ (см. табл. 3). Поскольку на развитие вишневой мухи существенное влияние оказывает микроклимат конкретного местонахождения, СЭТ не может гарантировать определения точного срока наступления отдельных фаз развития $R$. cerasi. Однако СЭТ может быть хорошим ориентиром для подготовки и планирования защитных мероприятий, если учитывать изменения степени активности мухи относительно изменений температуры воздуха (при температуре ниже $15-16^{\circ} \mathrm{C}$ прекращается спаривание и откладка яиц, удлиняется период эмбрионального развития) и интенсивности дождя (сильный дождь может приводить к гибели имаго) $(4,14,39)$. Более надежную информацию по определению начала и динамики лета можно 
получить, применяя (наряду с вычислением СЭТ) желтые клеевые ловушки и дополняя их визуальным наблюдением, поскольку степень зрелости и качество плодов также влияют на скорость развития фитофага. Этот факт отмечали другие исследователи $(32,40)$, его же подтвердили и наши данные, указывающие, что на черешне вылет и темпы развития мухи примерно на 1 нед опережают таковые на вишне $(7,41,42)$. Следует отметить, что определение более точных сроков проведения защитных мероприятий особенно важно при применении биологических средств защиты растений, имеющих значительно меньшую продолжительность действия, чем химические (3).

В отличие от южных регионов, где ранние сорта, как правило, уходят от повреждения вишневой мухой, поскольку к началу массовой откладки яиц фитофагом плоды созревают $(25,39)$, в ЦН3 поврежденность этих сортов в зависимости от условий года достигает 7-21\%. Однако большая часть личинок не успевает закончить питание и удаляется с насаждений вместе с собранными плодами. Наибольшая степень поврежденности отмечается у сортов позднего срока созревания (61-75 \%), но и у них, как и на сортах среднего срока созревания, часть личинок не успевает уйти на окукливание до сбора плодов из-за продолжительности и неравномерности периода выхода мухи из диапаузы. Несмотря на то, что максимальную численность мухи отмечали в саду к периоду полного созревания плодов поздних сортов вишни (см. рис. 2), лёт продолжался и после завершения массового сбора урожая (в течение 2-5 сут), хотя и со значительно меньшей интенсивностью. Известно, что репродукционный потенциал самок к этому времени резко снижается, в последние дни лёта они не откладывают яйца (29), но некачественный сбор плодов создает условия для успешного завершения периода питания личинок и существенно увеличивает зимующий (диапаузирующий) запас вредителя.

Следует отметить, что в созданных нами полуискусственных условиях содержания 53,2 \% пупарий не превратились в имаго. Это значительно больше, чем при выращивании в лаборатории, где гибель куколок составляет 5-25 \% (33), но меныше, чем показатели в природных условиях обитания, представленные для других регионов $(35,36)$.

Таким образом, в условиях Центрально-Нечерноземной зоны Российской Федерации имеет место как одногодичный, так и двухгодичный период диапаузы Rhagoletis cerasi L. При этом доля вылетевших мух после одногодичной диапаузы составляла 89,7 \%, а после двухгодичной $-10,3 \%$ от общего количества вылетевших мух. На третий год в садках мух не обнаруживали, что могло быть связано как с биоэкологическими особенностями северной популяции, так и с влиянием стрессовых факторов биотического (проникновение и накопление хищников, паразитов, возбудителей болезней в садках) и абиотического характера. В условиях ЦНЗ $R$. cerasi повреждала сорта вишни всех сроков созревания: ранние - на 7-21 \%, средние - на 38-57 \%, поздние - на 61-75 \%. Начало вылета имаго после зимней диапаузы сильно колебалось как по датам (от 3 до 33 сут), так и по сумме эффективных температур (СЭТ от 191,9 до 268,6 ${ }^{\circ} \mathrm{C}$ ). Такая же тенденция наблюдалась и для других стадий развития вредителя: до 27 сут или от 227,4 до $285,1{ }^{\circ} \mathrm{C}$ - для начала откладки яиц, от 2 до 24 сут или от 290,3 до $347,1{ }^{\circ} \mathrm{C}$ - для начала отрождения личинок, от 5 до 20 сут или от 481,4 до $559,9{ }^{\circ} \mathrm{C}$ - для начала ухода личинок на окукливание. Продолжительность периода лёта имаго в годы наблюдений занимала от 
40 до 69 сут. Надежный метод сигнализации и мониторинга динамики лета $R$. cerasi - применение желтых клеевых ловушек с использованием для ориентира СЭТ и визуального наблюдения, в том числе за качеством и степенью зрелости плодов.

\author{
ФГБНУ Всероссийский селекционно-технологический \\ институт садоводства и питомниководства, \\ 115598 Россия, г. Москва, ул. Загорьевская, 4, \\ e-mail: adzejnalov@yandex.ru $₫$
}

Поступила в редакцию

13 июля 2019 года

Sel'skokhozyaistvennaya biologiya [Agricultural Biology], 2020, V. 55, № 1, pp. 174-183

\title{
BIOECOLOGICAL FEATURES OF CHERRY FLY Rhagoletis cerasi (L. 1758) (Diptera: Tephritidae) DEVELOPMENT IN THE CENTRAL NON-CHERNOZEM ZONE OF RUSSIA
}

\author{
A.S. Zeynalov
}

All-Russian Horticultural Institute for Breeding, Agrotechnology and Nursery, 4, ul. Zagor'evskaya, Moscow, 115598 Russia, e-mail adzejnalov@yandex.ru ( $₫$ corresponding author)

ORCID:

Zeynalov A.S. orcid.org/0000-0001-5519-2837

The author declare no conflict of interests

Received July 13, 2019

doi: 10.15389 /agrobiology.2020.1.174eng

\section{Abstract}

Cherry fruit fly (Rhagoletis cerasi (L. 1758) (Diptera: Tephritidae)) in Central non-Chernozem zone of Russia appeared in the late 1990th-early 2000th, which is associated with global warming and the significant expansion in the acreage of forage plants in this region. Due to ecological plasticity the fly has quickly adapted to local conditions of habitat, and annually flies in a large number. This paper is the first to investigate dates of the flight start, dynamics and duration depending on weather conditions, the periods of egg laying, hatching and feeding of larvae, terms of cocoon formation in soil, and also the peculiarities of the pest diapause under the conditions of Central nonChernozem Russia. Damage of fruits in cherry varieties of different time of ripening was also assessed. Based on these data, effective methods for monitoring the phytophage are proposed. The studies were carried out in 2016-2018 in the cherry plantations of the All-Russian Horticultural Institute for Breeding, Agrotechnology and Nursery (ARHIBAN, Moscow Province, Leninskii District, $55.47^{\circ}$ n.1., $37.7^{\circ}$ e.1., $124 \mathrm{~m}$ above sea level) on cherry (Prunus cerasus L.) varieties of early (Sania, Bagryanaya), middle (Molodezhnaya, Volochaevka) and late (Malinovka, Apukhtinskaya) ripening periods. To the end, the research is targeted to improve monitoring methods, increase the efficiency and environmental safety of protective measures. The harsh conditions of the northern horticultural zone had a significant impact on the bioecology of the northern phytophage population. Depending on the weather conditions, the beginning and duration of flying, egg laying, hatching of larvae, and pupation vary greatly from year to year. The beginning of flies in different years was observed when the sum of effective temperatures (SET) above $10{ }^{\circ} \mathrm{C}$ from $191.9{ }^{\circ} \mathrm{C}$ to $268.6{ }^{\circ} \mathrm{C}$, with the difference in dates from 3 to 33 days; oviposition occurred at $227.4{ }^{\circ} \mathrm{C}$ to $285.1{ }^{\circ} \mathrm{C}$, with the difference in dates to 27 days; hatching of larvae occurred at $290.3{ }^{\circ} \mathrm{C}$ to $347.1{ }^{\circ} \mathrm{C}$, with the difference in dates from 2 to 24 days; the pupation occurred at $481.4^{\circ} \mathrm{C}$ to $559.9^{\circ} \mathrm{C}$, with the difference in dates from 5 to 22 days. The feeding period of the larvae ranged from 18 to 26 days, and the imago flying period from 40 to 69 days. In the conditions if Central non-Chernozem Russia, both one-year and two-year diapauses $R$. cerasi are possible. In keeping larvae in special cages (under trees in the garden), after the first winter diapause, only $42.0 \%$ of the overwintered individuals turned into adults. After the second winter diapause, those were $4.8 \%$ of the initial number of larvae gone on diapause. In the third year, no flies were recorded. In two years, only $46.8 \%$ of the individuals who went into diapause turned into adults, the rest died for various reasons. Also, the damage of cherry fruits varied from $7 \%$ to $21 \%$ for the early cultivars, from $38 \%$ to $57 \%$ for the middle-ripening cultivars, and from $61 \%$ to $75 \%$ for lthe ate-season maturing cultivars. Determination of $R$. cerasi phenophases based on calendar dates and phenophases of the host plant gives contradictory results in different years. Bilateral yellow glue traps combined with SET estimates and visual control of fruit ripening can improve $R$. cerasi monitoring to enable effective protective measures.

Keywords: insect, Diptera, Rhagoletis cerasi L., pest, bio-ecology, diapause, sum of effective temperatures. 


\section{R E F E R E N C ES}

1. Kovanci O.B., Kovanci B. Reduced-risk management of Rhagoletis cerasi files (host race Prunus) in combination with a preliminary phenological model. Journal of Insect Science, 2006, 6(1): 34 (doi: 10.1673/031.006.3401).

2. Özdem A., Kılınçer N. The effectiveness of the trap types and lures used for mass trapping to control cherry fruit fly [Rhagoletis cerasi (L., 1758)] (Diptera: Tephritidae). Munis Entomology and Zoology, 2009, 4(2): 371-377.

3. Daniel C., Grunder J. Integrated management of European cherry fruit fly, Rhagoletis cerasi (L.): situation in Switzerland and Europe. Insects, 2012, 3(4): 956-988 (doi: 10.3390/insects3040956).

4. Mohamadzade N.S., Rasoulian G.R. A review of fruit files of the genus Rhagoletis (Diptera: Tephritidae) of Iran and bordering countries, with the key to species. Vestnic Zoologii, 2009, 43(1): 25-30 (doi: 10.2478/v10058-009-0003-0).

5. Vasil'eva L.A. Materialy Mezhdunarodnoi nauchno-prakticheskoi konferentsii «Biologicheskaya zashchita rastenii - osnova stabilizatsii agroekosistem» [Mat. Int. Conf. «Biological plant protection - the basis for sustainable agroecosystems»]. Krasnodar, 2010, tom 6: 381-387 (in Russ.).

6. Zeinalov A.S. Zashchita i karantin rastenii, 2013, 8: 39-40 (in Russ.).

7. Zeinalov A.S. Osnovnye vrediteli i bolezni plodovykh kul'tur i sistemy meropriyatii po ogranicheniyu $i k h$ vredonosnost $i$ The main pests and diseases of fruit crops and the measures to limit their harmfulness]. Moscow, 2018 (in Russ.).

8. Dowell R.V., Penrose R.L. Distribution and phenology of Rhagoletis fausta (Osten Sacken 1877) and Rhagoletis indifferens Curran 1932 (Diptera: Tephritidae) in California. The Pan-Pacific Entomolgist, 2012, 88(2): 130-150 (doi: 10.3956/0031-0603-88.2.130).

9. Smith T.J. Western cherry fruit fly (Rhagoletis indifferens \{Curran\}) and its management in the pacific northwest United States of America. 2017. Available: http;//extension.wsu.edu/ chelandouglas/agriculture/treefruit/pestmanagement/cherry-fruitfly. Accessed: 10.01.2019.

10. Yee W.L. Efficacies of Rhagoletis cerasi (Diptera: Tephritidae) traps end ammonium lures for western cherry fruit fly. Journal of Insect Science, 2018, 18(3): 14; 1-8 (doi: 10.1093/jisesa/iey054).

11. Wakie T.T., Yee W.L., Neven L.G. Assessing the risk of establishment of Rhagoletis cerasi (Diptera: Tephritidae) in the United States and globally. Journal of Economic Entomology, 2018, 111(3): 1275-1284 (doi: 10.1093/jee/toy054).

12. Vasil'ev V.P., Livshchits I.Z. Vrediteli plodovykh kul'tur [Pests of fruit crops]. Moscow, 1984 (in Russ.).

13. Blümel S., Keck M., Nowotny N., Fiedler W., Russ K. Nachweis und Therapie von Rickettsialike organisme (RLO's) in den Ovarien der europäischen kirschfruchtfliege (Rhagoletis cerasi L.; Trypetidae): Ein Beitrag zur Frage der unidirektionalen Kreuzungssterilitat dieser Art. Pflanzenschutzberichte, 1991, 52: 41-47.

14. Moraiti C.A., Nakas Ch.T., Köppler K., Papadopoulos N.T. Geographical variation in adult lifehistory traits of the European cherry fruit fly Rhagoletis cerasi (Diptera: Tephritidae). Biological Journal of the Linnean Society, 2012, 107(1): 137-152 (doi: 10.1111/j.1095-8312.2012.01930.x).

15. Augustinos A.A., Asimakopoulou A.K., Moraiti C.A., Mavragani-Tsipidou P., Papadopoulos N.T., Bourtzis K. Microsatellite and Wolbachia analysis in Rhagoletis cerasi natural populations: population structuring and multiple infections. Ecology and Evololution, 2014, 4(10): 1943-1962 (doi: 10.1002/ece3.553).

16. Schuler H., Köppler K., Daxböck-Horvath S., Rasool B., Krumböck S., Schwarz D., Hoffmeister T.S., Schlick-Steiner B.C., Steiner F.M., Telschow A., Stauffer Ch., Arthofer W., Riegler M. The hitchhiker's guide to Europe: the infection dynamics of an ongoing Wolbachia invasion and mitochondrial selective sweep in Rhagoletis cerasi. Molecular Ecolology, 2016, 25(7): 1595-1609 (doi: 10.1111/mec.13571).

17. Bakovic V., Schebeck M., Telschow A., Stauffer C., Schuler H. Spatial spread of Wolbachia in Rhagoletis cerasi populations. Biolology Letters, 2018, 14(5): 20180161 (doi: 10.1098/rsbl.2018.0161).

18. Schebeck M., Feldkirchner L., Stauffer Ch., Schuler H. Dynamics of an ongoing Wolbachia spread in the European cherry fruit fly, Rhagoletis cerasi (Diptera: Tephritidae). Insects, 2019, 10(6): 172 (doi: 10.3390/insects10060172).

19. Schuler H., Kern P., Arthofer W., Vogt H., Fischer M., Stauffer C., Riegler M. Wolbachia in parasitoids attacking native European and introduced Eastern cherry fruit flies in Europe. Environmental Entomology, 2016, 45(6): 1424-1431 (doi: 10.1093/ee/nvw137).

20. Riegler M., Stauffer C. Wolbachia infections and superinfections in cytoplasmically incompatible populations of the European cherry fruit fly Rhagoletis cerasi (Diptera: Tephritidae). Molecular Ecology, 2002, 11(11): 2425-2434 (doi: 10.1046/j.1365-294X.2002.01614.x).

21. Kounatidis I., Papadopoulos N., Bourtzis K., Mavgarani-Tsipidou P. Genetic and cytogenetic analysis of the fruit fly Rhagoletis cerasi (Diptera: Tephritidae). Genome, 2008, 51(7): 479-491 (doi: 10.1139/G08-032).

22. Arthofer W., Riegler M., Schneider D., Krammer M., Miller W.J., Stauffer C. Hidden Wolbachia 
diversity in field populations of the European cherry fruit fly, Rhagoletis cerasi (Diptera: Tephritidae). Molecular Ecology, 2009, 18(18): 3816-3830 (doi: 10.1111/j.1365-294X.2009.04321.x).

23. White I.M., Elson-Harris M.M. Fruit flies of economic significance: their identification and bionomics. CAB International, Wallingford, Oxon, UK: 1992.

24. Schwarz D., McPheron B.A., Hartl G.B., Boller E.F., Hoffmeister T.S. A second case of genetic host races in Rhagoletis? A population genetic comparison of sympatric host populations in the European cherry fruit fly, Rhagoletis cerasi. Entomologia Experimentalis et Applicata, 2003, 108(1): 11-17 (doi: 10.1046/j.1570-7458.2003.00065.x).

25. Stamenkovic S., Garic R., Milenkovic S., Nikolic M., Stamenkovic T. Susceptibility of some sweet cherry cultivars to Rhagoletis cerasi L. (Diptera, Tephritidae). Acta Horticulturae, 1996, 410: 555-560 (doi: 10.17660/actahortic.1996.410.91).

26. Balázs K., Jenser G. Significance of the parasitoids and predators in IPM of sour-cherry. IOBC/wprs Bulletin, 2004, 27(5): 3-7.

27. Katsoyannos B. European cherry fruit fly, Rhagoletis cerasi (L.) (Diptera: Tephritidae). In: Encyclopedia of entomology. J.L. Capinera (ed.). Springer, Dordrecht, 2008 (doi: 10.1007/9781-4020-6359-6_3687).

28. Nježić B., Pećanin D., Đurić G. Improvement of management of Rhagoletis cerasi in Bosnia and Herzegovina based on a phenological model. Proceedings of the Latvian Academy of Sciences. Section B. Natural, Exact, and Applied Sciences, 2017, 71(3): 229-232 (doi: 10.1515/prolas-20170038).

29. Moraiti C.A., Nakas C.T., Papadopoulos N.T. Prolonged pupal dormancy is associated with significant fitness cost for adults of Rhagoletis cerasi (Diptera: Tephritidae). Journal of Insect Physiology, 2012, 58(8): 1128-1135 (doi: 10.1016/j.jinsphys.2012.05.012).

30. Dospekhov B.A. Metodika polevogo opyta [Methods of field trials]. Moscow, 1985 (in Russ.).

31. Papanastasiou S.A., Nestel D., Diamantidis A.D., Nakas C.T., Papadopoulos N.T. Physiological and biological patterns of a highland and a coastal population of the European cherry fruit fly during diapause. Journal of Insect Physiology, 2011, 57(1): 83-93 (doi: 10.1016/j.jinsphys.2010.09.008).

32. Moraiti C.A., Nacas C.T., Papadopoulos N.T. Diapause termination of Rhagoletis cerasi pupae is regulated by local adaptation and phenotypic plasticity: escape in time through bet-hedging strategies. Journal of Evolutionary Biology, 2014, 27(1): 43-54 (doi: 10.1111/jeb.12273).

33. Papanastasiou S.A., Papadopoulos N.T. Description of Rhagoletis cerasi (Diptera: Tephritidae) pupal developmental stages: indications of prolonged diapause. Journal of Insect Science, 2014, 14(1): 156-160 (doi: 10.1093/jisesa/ieu018).

34. Hahn D.A., Denlinger D.L. Meeting the energetic demands of insect diapause: nutrient storage and utilization. Journal of Insect Physiology, 2007, 53(8): 760-773 (doi: 10.1016/j.jinsphys.2007.03.018).

35. Herz A., Köppler K., Vogt H. Kann der Einsatz entomopathogener nematoden zur nachhaltigen bekämpfung der kirschfruchtfliege beitragen? Proceedings of the 9. Wissenschaftstagung Ökologischer Landbau. S. Zikeli, W. Claupein, S. Dabbert, B. Kaufmann, T. Müller, A. Valle Zárate (eds.). Verlag Dr. Köster, Berlin, Germany, Universität Hohenheim, 2007: 277-280.

36. Daniel C. Entomopathogenic fungi as a new strategy to control the European cherry fruit fly Rhagoletis cerasi Loew (Diptera: Tephritidae). PhD thesis. Technische Universität München, Germany, 2009.

37. Baker C.R.B., Miller G.W. The effect of temperature on the post-diapause development on four geographical populations of the European cherry fruit fly (Rhagoletis cerasi). Entomologia Experimental et Applicata, 1978, 23(1): 1-13 (doi: 10.1111/j.1570-7458.1978.tb02725.x).

38. Jarošík V., Honěk A., Magarey R.D., Skuhrovec J. Developmental database for phenology models: related insect and mite species have similar thermal requirements. Journal of Economic Entomology, 2011, 104(6): 1870-1876 (doi: 10.1603/EC11247).

39. Vasil'eva L.A. Biologo-ekologicheskoe obosnovanie elementov integrirovannoi zashchity chereshni $i$ vishni ot vishnevoi mukhi Rhagoletis cerasi L. (Diptera: Trypetidae) v usloviyakh Krasnodarskogo kraya. Avtoreferat kandidatskoi dissertatsii [Biological and ecological basis of integrated protection from cherry fly Rhagoletis cerasi L. (Diptera: Trypetidae) in the Krasnodar Territory. PhD Thesis]. Voronezh, 2009 (in Russ.).

40. Karlidag H., Ercisli S., Sengul M., Tosun M. Physico-chemical diversity in fruits of wildgrowing sweet cherries (Prunus avium L.). Biotechnology and Biotechnological Equipment, 2009, 23(3): 1325-1329 (doi: 10.1080/13102818.2009.10817663).

41. Zeinalov A.S., Upadysheva G.Yu. V sbornike: Selektsiya i sortorazvedenie sadovykh kul'tur [In: Horticulture: selection and cultivation]. Orel, 2015, tom 2: 84-86 (in Russ.).

42. Zeinalov A.S. Materialy Vserossiiskoi konferentsii s mezhdunarodnym uchastiem «Monitoring $i$ biologicheskie metody kontrolya vreditelei i patogenov drevesnykh rastenii: ot teorii $k$ praktike» [Proc. All-Russian Conf. «Monitoring and biocontrol of pests and pathogens of woody plants: from theory to practice»]. Krasnoyarsk, 2016: 87-88 (in Russ.). 